\title{
Are all helicobacters equal? Mechanisms of gastroduodenal pathology and their clinical implications
}

\author{
A T R Axon
}

\section{Summary}

Most cases of peptic ulcer disease, gastric mucosa associated lymphoid tissue (MALT) lymphoma and cancer of the distal stomach are complications of Helicobacter pylori infection. However, as with most infections not all patients who contract the infection develop the complications of the disease. The other factors that influence the likelihood of problems arising are the virulence of the infecting organism, the genetic constitution and age of the host, and environmental factors. This paper focuses mainly upon the effect of strain differences and the causation of serious disease.

There is considerable genetic variation between the different strains of $H$ pylori, some causing a more severe inflammatory response in the host than others. These strains are also associated with a greater likelihood of causing peptic ulcer, atrophic gastritis and intestinal metaplasia and gastric cancer. There is some evidence to suggest that these more virulent organisms may also protect the host from the development of reflux oesophagitis and possibly cancer in the region of the gastro-oesophageal junction. The major difference between virulent and relatively avirulent organisms depends upon the presence of the cag pathogenicity island, a segment of DNA that has been acquired possibly from another organism and is now incorporated within the helicobacter genome. Its presence is associated with the secretion of the vacuolating toxin which is a protein known to cause damage in cell culture and in vivo.

As CagA, one of the proteins produced by the pathogenicity island, is highly antigenic, people infected with more virulent strains can be identified by a blood test. Currently controversy surrounds the question as to whether all patients with $H$ pylori should be treated for infection or whether medication should be reserved for those who already have the complications of the infection, or individuals infected with the more virulent strain of the organism.

\section{Difference between bacteria}

Bacteria, in common with all biological systems, are in a continuous state of evolution, their genetic make-up subtly altering with succeeding generations. Until recently, bacteria were divided into species on the basis of their metabolic activity and chemical structure and an evolutionary family tree was derived based on phenotypic characteristics. Species were subdivided into different types according to the immune reaction they evoked (serotyping) or by susceptibility to sets of viruses (phage typing). Increasingly, individual species and strains are identified and further subdivided by the molecular structure of the DNA contained in their chromosome (genotype). $H$ pylori is relatively inert (few positive phenotypic characteristics) and therefore has been generally typed using molecular methods which give highly detailed "fingerprints". This organism inhabits the human stomach for many bacterial generations and evolves separately in each host such that it is unusual to find two identical strains in different hosts except in families or institutions where a specific strain may recently have been transmitted from one individual to another.

\section{Variation between strains of $\boldsymbol{H}$ pylori}

The helicobacter genome sequence was published in $1997 .{ }^{1}$ It is a relatively simple organism with 1.7 million nucleotides (dependent upon the strain of the organism). These nucleotides represent approximately 1600 genes, $^{2}$ each of which code for a separate protein. Of these, $55 \%$ are found in other organisms, but $45 \%$ are unique to $H$ pylori. Mutations in nucleotides give rise to differences between strains and affect the behaviour of the organism such that some are selected out in preference to others-for example, in the development of antibiotic resistance.

There is, however, another way in which the genetic constitution of an organism may change. Certain bacteria are able to transmit segments of DNA to a different strain or species of organism. These small packets of DNA may remain separate from the main chromosome of the recipient as a plasmid or may be incorporated into the chromosome itself. If it codes for a series of virulence characteristics it may be considered to be a pathogenicity island (PAI). ${ }^{3}$ If this extra piece of DNA works to the biological advantage of that organism it will survive and the "foreign" segment of DNA will become part of the genome of the new strain.

The virulence of $H$ pylori and its ability to damage the host seem to depend both on the nature of the chromosome (in particular the segment that codes for the vacuolating toxin $^{4}$ ), and also from what appears to be

Abbreviations used in this paper: MALT, mucosa associated lymphoid tissue; PAI, pathogenicity island.
Diseases

The General Infirmary at Leeds,

Great George Street, Leeds LS1 3EX, UK 
an alien insertion of DNA within the chromosome-the cytotoxin associated pathogenicity island or cagPAI.

\section{The pathogenicity island}

The helicobacter chromosome is circular in shape and contains the cagPAI which is a 40 kilobase segment of DNA that codes for around 40 proteins. The proportion of bases that make up the PAI differs from that in the rest of the helicobacter chromosome suggesting that this DNA has come from an alien source. Furthermore, the ends of the DNA sequence have repeats of a nature which lend support to this hypothesis. It is unclear from which organism the PAI was derived; however, it has features in common with certain sequences in Escherichia coli, Yersinia pestis and Vibrio cholerae. The reason why it is termed a PAI is because organisms that contain this sequence of DNA cause a more severe inflammation in the host mucosa. The island is analogous to the plasmids and insertions found in $E$ coli that cause adhesion, invasion and toxin production. The function of the PAI is not clearly understood, but it is believed to be involved in the export of macromolecules important in parasite/host interactions.

The cytotoxin associated antigen (CagA) One of the 40 genes contained in the PAI is $\operatorname{cag} A$ which codes for the protein CagA. CagA is a $120 \mathrm{kDa}$ protein that was identified soon after $H$ pylori had been discovered. ${ }^{6}{ }^{7}$ The reason for this is that patients readily develop antibodies to CagA. cag $A$ is the cytotoxin associated gene $A$, and it is found in organisms that secrete the vacuolating toxin. ${ }^{8}$ Neither it nor the PAI actually produces the toxin. Indeed $v a c A$, the gene that produces the vacuolating toxin, is not even part of the PAI. For some reason, however, VacA (the vacuolating toxin) is not usually secreted by $H$ pylori unless the PAI is present. If the cag $A$ gene is "nullified" experimentally leaving the rest of the PAI intact the organism is still capable of secreting the vacuolating toxin. ${ }^{9}$

The vacuolating toxin (VacA)

The vacuolating toxin was discovered in $1988 .{ }^{10}$ It is an $87 \mathrm{kDa}$ protein secreted by helicobacter strains that contain the PAI. It causes vacuolation in cell culture in vitro and in vivo damages mouse gastric epithelium. ${ }^{11}$ It is activated at a low $\mathrm{pH}$ and is resistant to acid and pepsin. vacA (the gene that codes for VacA) is situated a variable, but significant distance from the PAI and varies between strains. ${ }^{12}$ The mid portion is divided into M1 and $\mathrm{M} 2$, and the signalling sequences into $\mathrm{S} 1$, $a$ and $b$ and S2. These differences are important in terms of the ability of the organism to secrete the active vacuolating toxin, the $S 1 / M 1$ genotype having this ability whereas S2/M2 does not. One possible explanation for these differences is that the strains possessing the VacAS1 genotype also contain the PAI. ${ }^{13}$
Factors responsible for clinical disease As with most infectious diseases helicobacter associated gastroduodenitis is influenced not only by the nature of the infecting strain, but also by host and environmental factors. The underlying pathology of the disease is one of acute and chronic inflammation affecting the stomach. When heterotopic gastric mucosa or areas of gastric metaplasia are present within the duodenum they may become infected and cause duodenitis. ${ }^{14}$ The inflammatory reaction within the stomach and duodenum impairs the mechanisms normally used by the host to protect against acid. Susceptible people are therefore at risk of developing the complications of $H$ pylori infection-duodenal and gastric ulcer. Long standing gastric inflammation leads to atrophy and intestinal metaplasia, conditions strongly associated with cancer of the body and distal stomach. It has been known for many years that host factors are also important in determining whether these complications will arise. Genetic differences-for example, sex and blood group, exert an influence ${ }^{15}$ as does the age of the host. Environmental factors are probably more important. Duodenal ulcer was excessively rare before the middle of the 19th century ${ }^{16}$ even though $H$ pylori was widespread at that time. The geographical differences in the incidence of gastric cancer and the international variation between duodenal and gastric ulcer prevalence confirm the importance of the environment. Some environmental factors are clear, namely smoking in duodenal ulcer, ${ }^{17}$ and the protective effect of dietary vegetables and fruit for gastric cancer. ${ }^{18}$ Another determinant appears to be the amount of gastric acid secreted by the host. ${ }^{19}$ Duodenal ulcer is a high secretory condition associated with an antral predominant gastritis whereas gastric ulcer and stomach cancer arise in individuals with pangastritis. It is not known whether these differences in acid secretion are caused by host or environmental factors, or a combination of both.

Influence of strain on clinical disease Individuals infected with a CagA positive strain of $H$ pylori have a more severe inflammatory reaction, a greater degree of gastric atrophy and intestinal metaplasia and a higher incidence of duodenal ulcer and intestinal type gastric cancer. ${ }^{20}{ }^{21}$ One study ${ }^{22}$ has suggested that infection with a CagA positive organism may protect against adenocarcinoma of the oesophagus and oesophagogastric junction. The strain, however, does not seem to influence whether the gastritis phenotype of the host will be antral predominant or a pangastritis. ${ }^{23}$ It seems, therefore, that host or environmental factors are responsible for the nature of the disease whereas the strain of the organism has an important influence on the severity of the disease and the likelihood of complications. Not all CagA positive infections lead to complications and serious disease may occur in patients infected with CagA negative bacteria. The ratio of CagA positive to CagA negative organisms varies in 
different populations, from approximately 30 to $80 \% .^{24}$ Many strains, some CagA positive, others CagA negative, may be found in a single host. $^{25}$

\section{Clinical implications}

The clinical approach to helicobacter infection has changed since its discovery in 1985. At that time most doctors were sceptical at the suggestion that the organism might be responsible for gastrointestinal disease. When, however, experiments were undertaken to test this hypothesis it quickly became apparent that helicobacter was indeed the major cause of peptic ulceration. Epidemiological work strongly supported the view that helicobacter was also a major player in the pathogenesis of gastric cancer and MALT lymphoma. There has never been a large body of evidence to suggest that the infection is responsible for functional dyspepsia; however, the fact that it invariably causes gastritis in the host and the risk of future disease has encouraged the view that the only good helicobacter is a dead one. As a result many primary health physicians and gastroenterologists treat all patients found to be $H$ pylori positive.

Gastric cancer is the second commonest cause of death from cancer worldwide and when the mortality from this disease is added to deaths arising from peptic ulcer, the complications associated with $H$ pylori infection represent a serious public health problem. ${ }^{26}$ Considerable energy and money is being spent in the search for a vaccine to eliminate the infection from mankind.

More recently cautionary voices have warned that the elimination of an organism distributed so widely in human hosts may not necessarily be advantageous. ${ }^{27}$ The observation that some helicobacters are less dangerous than others and seem to cohabit with the host without giving rise to clinical disease argues that it is unnecessary to cure all infection and indeed to do so might even be meddlesome if the organism provides some (as yet unknown) benefit. Some authors have drawn attention to the increased incidence of gastro-oesophageal reflux disease in communities where helicobacter infection rates are falling ${ }^{28}$ and others suggest infection with CagA positive $H$ pylori may reduce the likelihood of Barrett's oesophagus and cancer of the gastro-oesophageal junction. ${ }^{22}$ Clearly these are areas that require further research. At present the concept of a "good" helicobacter appears to be a myth because it is just those CagA positive organisms that create mayhem in the distal stomach and duodenum that are the ones that provide apparent protection for the oesophagogastric junction.

The prevalence of infection in the West is falling and is likely to continue to decline as the standard of living rises. The long term outcome therefore is not in the hands of the medical profession. In the short and medium term, however, those infected with $H$ pylori have a substantially increased risk of peptic ulcer and gastric cancer which is why many doctors believe eradication of helicobacter to be the safest policy.

One objection raised to this approach is that the indiscriminate use of antibiotics is likely to lead to widespread antibiotic resistance. However this argument, if anything, supports the view that we should eradicate helicobacter. Antibiotics are already used indiscriminately throughout whole populations, and it is for this reason that helicobacter infection in the developing world is usually resistant to metronidazole. The prescription of antibiotics in the developed world amounts to the equivalent of more than one course for every man, woman and child per year. Treatment of $H$ pylori would amount to a relatively small increase in the total amount of antibiotics prescribed. There is an advantage to be gained by treating the infection while it remains sensitive to such antibiotics as the macrolides.

I am grateful to Dr David Tompkins, Director of the Public Health Laboratory Service, Leeds, UK, for his advice in the preparation of this publication.

1 Tomb J-F, White O, Kerlavage AR, et al. The complete sequence of the gastric pathogen Helicobacter pylori. Nature 1997;388:539-47.

2 Dorrell N, Wren BW. From genes to genome biology: a new era in Helicobacter pylori research. Gut 1998;42:451-3.

3 Covacci A, Falkow S, Censini S, et al. The cag pathogenicity island of Helicobacter pylori: origin, molecular biology and relevance to virulence. In: Moran AP, O'Morain CA, eds. Pathogenesis and host response in Helicobacter pylori infections. Bad Homburg: Normed Verlag, bacter pylori

4 Atherton JC, Cao P, Peek RM, et al. Mosaicism in vacuolating cytotoxin alleles of Helicobacter pylori: association of specific vacA types with cytotoxin production and peptic ulceration. F Biol Chem 1995;270:17771-7.

5 Covacci A, Falkow S, Berg DE, et al. Did the inheritance of a pathogenicity island modify the virulence of Helicobacter pylori? Trends Microbiol 1997;5:205-8.

6 Cover TL, Dooley CP, Blaser MJ. Characterisation of and human serologic response to proteins in Helicobacter pylori broth culture supernatants with vacuolizing cytotoxin activity. Infect Immun 1990;58:603-10.

7 Crabtree JE, Taylor JD, Wyatt JI, et al. Mucosal IgA recognition of Helicobacter pylori $120 \mathrm{kDa}$ protein, peptic ulceration and gastric pathology. Lancet 1991;338:332-5.

8 Leunk RD. Production of a cytotoxin by Helicobacter Leunk RD. Production of a cytotoxin by
pylori. Rev Infect Dis 1991;13(suppl):S686-9.

9 Tummuru MKR, Cover TL, Blaser MJ. Mutation of the cytotoxin cagA gene does not affect the vacuolating cytotoxin activity of Helicobacter pylori. Infect Immun 1994;62:2609-13.

10 Leunk RD, Johnson PT, David BC, et al. Cytotoxic activity in broth-culture filtrates of Campylobacter pylori. $\mathcal{F} \mathrm{Med}$ Microbiol 1988;26:93-9.

11 Telford JL, Ghiara P, Dellorco M, et al. Gene structure of the Helicobacter pylori cytotoxin and evidence of its key role in gastric disease. F Exp Med 1994;179:1653-8.

12 Atherton JC. The clinical relevance of strain types of Helicobacter pylori. Gut 1997;40:701-3.

13 Atherton JC, Peek RM, Tham KT, et al. Clinical and pathological importance of heterogeneity in vacA, the vacuolating cytotoxin gene of Helicobacter pylori. Gastroenterology 1997;112:92-9.

14 Wyatt JI, Rathbone BJ, Dixon MF, et al. Campylobacter pyloridis and acid induced gastric metaplasia in the pathopyloridis and acid induced gastric metaplasia in the
genesis of duodenitis. F Clin Pathol 1987;40:841-8.

15 Clark CA, Edwards JW, Haddock DRW, et al. ABO blood groups and secretor characters in duodenal ulcer. $B M \mathcal{F}$ 1956;2:725-31

16 Jennings D. Perforated peptic ulcer. Changes in agencidence and sex-distribution in the last 150 years. Lancet 1940;i:395-7, 444-7.

17 Friedman GD, Siegelaab AB, Seltzer CC. Cigarettes, alcohol, coffee and peptic ulcer. N Engl f Med 1974;290: 469-73.

18 Buiatti E, Palli D, Decarli A, et al. A case-control study of gastric cancer and diet in Italy: II. Association with gastric cancer and diet in Italy: II.

19 Lee A, Dixon MF, Danon SJ, et al. Local acid production and Helicobacter pylori: a unifying hypothesis of gastroduoden. 
20 Parsonnet J, Friedman GD, Orentreich N, et al. Risk Parsonnet J, Friedman GD, Orentreich $\mathrm{N}$, et al. Risk
for gastric cancer in people with CagA positive or CagA
negative Helicobacter pylori infection. Gut $1997 ; 40: 297-$ negative
301 .
Blaser

21 Blaser MJ, Perez-Perez GI, Kleanthous H, et al. Infection with Helicobacter pylori strains possessing cagA is associated with an increased risk of developing adenocarcinoma of the stomach. Cancer Res 1995;55:2111-15.

22 Chow W-H, Blaser MJ, Blot WJ, et al. An inverse relation between cagA strains of Helicobacter pylori infection and risk of esophageal and gastric cardia adenocarcinoma. Cancer Res 1998;58:588-90.

23 Warburton VJ, Everett S, Mapstone NP, et al. Clinical and histological associations of cagA and vacA genotypes in Helicobacter pylori gastritis. $\mathcal{F}$ Clin Pathol 1998;51:55-61.
24 Perez-Perez GI, Bhat N, Gaensbauer J, et al. Country specific constancy by age in cagAt proportion of Helicobacter pylori infections. Int f Cancer 1997;72:453-6.

25 Figura N, Vindigni C, Covacci A, et al. cagA positive and negative Helicobacter pylori strains are simultaneously present in the stomach of most patients with non-ulcer dyspepsia: relevance to histological damage. Gut 1998;42: $772-8$.

26 Axon ATR, Forman D. Helicobacter gastroduodenitis: a serious infectious disease. BMF 1997;314:1430-1.

27 Blaser MJ. Not all Helicobacter pylori strains are created equal: should all be eliminated? Lancet 1997;349:1020-2.

28 El-Serag HB, Sonnenberg A. Opposing time trends of peptic ulcer and reflux disease. Gut 1998;43:327-33. 